\title{
Global Soil and Sediment transfers in the Anthropocene
}

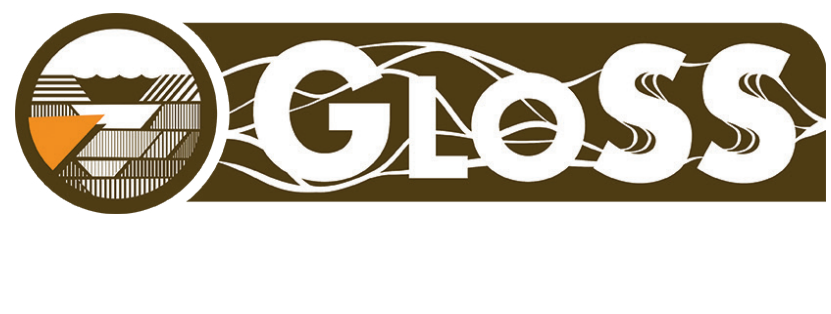

Thomas Hoffmann ${ }^{1}$, D. Penny², G. Stinchcomb³, V. Vanacker ${ }^{4}$ and X.X. Lu ${ }^{5}$

\begin{abstract}
Anthropogenic soil erosion reduces soil productivity, compromises freshwater ecosystem services, and drives geomorphic and ecological change in rivers and floodplains. It is now well accepted that the rate of anthropogenic soil erosion exceeds the rate of soil production by several orders of magnitude in many parts of Earth (Montgomery 2007), threatening the sustainability of food production that is so essential to human well-being. Deposition of the eroded soil downstream has profoundly altered the structure and function of fluvial and deltaic ecosystems, often with negative impacts on the societies and economies that depend on them (Hoffmann et al. 2010). The legacy of these impacts exerts strong influence over modern and future ecosystem functions. In many agricultural ecosystems, natural processes no longer primarily control soil erosion and deposition, and greatly altered sediment fluxes are a key marker of the Anthropocene (Syvitski and Kettner 2011).
\end{abstract}

The vulnerability of soils to human-induced erosion is highly variable in space and time dependent on climate, geology, the nature and duration of land use, and topography. Our knowledge of the mechanistic relationships between soil erodibility, land use, and climate is well developed. However, the global heterogeneity of land use history and the co-occurrence of other erosion-relevant factors such as climate variability have prevented us from sufficiently understanding the global patterns of long-term soil erosion and fluvial sediment flux and storage, and quantifying their budgets.

\section{Objectives}

GloSS (Global Soil and Sediment transfers in the Anthropocene) will analyze the global pattern of past and present anthropogenic soil erosion, and the transfer and deposition of sediment. It aims to determine the sensitivity of soil resources and sediment routing systems to varying land use types during the period of agriculture, under a range of climate regimes and socio-ecological settings.

To achieve this objective, GloSS will integrate the scientific domains of geomorphology, paleoecology, archaeology, and history. GloSS focuses on the local and regional impact of anthropogenic activities on soil erosion and sediment transfer through fluvial systems in different socio-ecological contexts since the onset of agriculture, which began in Eurasia as early as approximately 8,000 years ago.

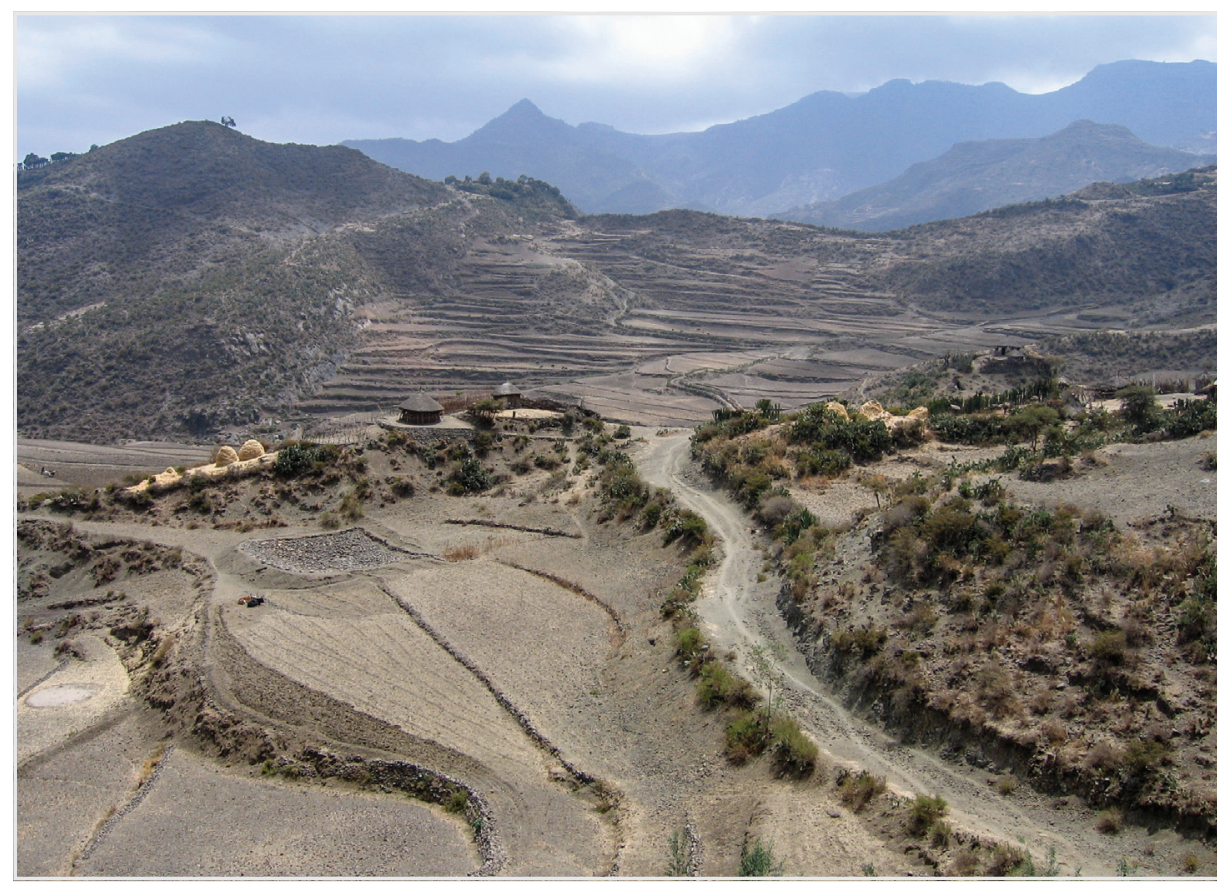

Figure 1: Smallholder rain-fed agriculture in the Ethiopian Highlands, Amhara Region, Ethiopia. Photo by Veerle Vanacker.

\section{GloSS therefore aims to:}

- Update the global network of scientists developing long-term soil erosion and sediment flux histories within socio-ecological systems, building on the work of the former Land Use and Climate Impacts on Fluvial Systems (LUCIFS) working group;

- Develop proxies and indices for human impact on rates of soil erosion and fluvial sediment transfer that are applicable on a global scale and throughout the Holocene:

- Create a global database of long-term $\left(10^{2}-10^{4}\right.$ years) human-accelerated soil erosion and sediment flux records;

- Identify hot spots of soil erosion and sediment deposition during the Anthropocene;

- Locate data-poor regions where particular socio-ecological systems are not well understood, as strategic foci for future work.

The objectives and goals of the GloSS working group sit at the nexus of climate, environment, and humanity and thus contribute to the interdisciplinary activities at the heart of the revised PAGES science structure and the Future Earth initiative.
Visit the GloSS webpage at: www.pages-igbp.org/workinggroups/gloss and sign up to our mailing list to keep up to date with the group's activities.

\section{AFFILIATIONS}

'Department of Geography, University of Bonn, Germany

${ }^{2}$ School of Geosciences, University of Sydney, Australia ${ }^{3}$ Watershed Studies Institute, Murray State University, USA

${ }^{4}$ Department of Geography, Louvain, Belgium ${ }^{5}$ Department of Geography, National University of Singapore

CONTACT

Thomas Hoffmann: thomas.hoffmann@uni-bonn.de REFERENCES

Hoffmann T et al. (2010) Global Planet Change 72: 87-98 Montgomery DR (2007) PNAS 104(33): 13268-13272 Syvistki JP, Kettner AJ (2011) Phil Trans R Soc London, Ser A 369: 957-975 